(c) American Dairy Science Association, 2004.

\title{
Lactation Performance and Feeding Behavior of Dairy Cows Supplemented Via Automatic Feeders with Soy Hulls or Barley Based Pellets
}

\author{
J. Miron, ${ }^{1}$ M. Nikbachat, ${ }^{1}$ A. Zenou, ${ }^{1}$ D. Ben-Ghedalia, ${ }^{1}$ R. Solomon, ${ }^{2}$ \\ E. Shoshani, ${ }^{2}$ I. Halachmi, ${ }^{3}$ N. Livshin, ${ }^{3}$ A. Antler, ${ }^{3}$ and E. Maltz ${ }^{3}$ \\ ${ }^{1}$ Institute of Animal Science, Department of Dairy Science, \\ ARO, Bet Dagan, Israel \\ ${ }^{2}$ Israeli Ministry of Agriculture, Extension Service, Bet Dagan, Israel \\ ${ }^{3}$ Institute of Agricultural Engineering, ARO, Bet Dagan, Israel
}

\begin{abstract}
The potential of soy hulls to replace barley grain in pellets supplemented to lactating cows was measured in automatic concentrate feeders (ACF). Thirty-six cows were divided into 2 equal groups and fed 1 of the 2 experimental pellet supplements individually for $7 \mathrm{wk}$. All cows were group-fed a basic mixture along the feeding lane ( $64 \%$ of dietary DM) plus a pelleted additive containing $50 \%$ barley or soy hulls as barley replacer, fed individually to each cow via the ACF in 6 feeding windows. Extent and rate of in vitro DM digestibility were similar for both types of pellets; however, NDF content and digestibility were higher in the soy hulls pellets. Average number of rewarded cow visits at the $\mathrm{ACF}$, pellets intake per meal, and accumulated intake of pellets $(8.64 \mathrm{~kg} / \mathrm{d} \mathrm{DM})$ were similar in the 2 experimental groups. Most pellets were consumed during day and night in the first $2 \mathrm{~h}$ after feeding windows were opened. Total visits per day in the ACF and the maximal interval between visits were similar for the 2 pellets, indicating similar attractiveness to the cow. Predicted intake of the basic mixture was similar in both groups (14.8 to $15.1 \mathrm{~kg}$ of DM/d). Higher milk fat content was observed in the soy hulls-fed cows, whereas higher milk protein content was found in the barley-fed cows. Milk yield was similar in both groups. Data suggest that replacement of barley pellets with soy hulls pellets may slightly enhance milk fat while reducing milk protein production for dairy herds using automatic milking systems.
\end{abstract}

(Key words: pelleted soy hulls, barley pellets, automatic concentrate feeder, milk production)

Abbreviation key: ACF = automatic concentrate feeder, AMS = automatic milking system, $\mathbf{B G}=$ barley

Received May 6, 2004.

Accepted August 16, 2004.

Corresponding author: J. Miron; e-mail: jmiron@volcani.agri. gov.il. grains, $\mathbf{E C M}=$ economically-corrected milk, $\mathbf{F W}=$ feeding windows, $\mathbf{S H}=$ soy hulls.

\section{INTRODUCTION}

With an automatic milking system (AMS), often called a milking robot, a cow is attracted to a robot by the concentrate feed which is supplied in the robot or in a concentrate feeder accessed only after visiting the robot (Halachmi, 2004). Therefore, more visits to the robot result in more intake of concentrate feed. Feeding concentrates while the cow is being milked in AMS may allow consumption of a high quantity of starchy grains within a short time. This could affect not only the appetite and feeding behavior of the cows, but also the rate and extent of NDF digestibility by ruminal bacteria, leading to further reduction in NDF intake and its possible use for milk fat production (Miron et al., 2004). It is therefore desirable to maintain, even with AMS, TMR feeding instead of depending only on concentrate feed supplied by a self-feeder, such as used in Europe where the robot was developed (Morita et al., 1996; Halachmi, 1999; Wagner-Storch and Palmer, 2003). The increasing use of robotic milking justifies a study that quantifies the maximum amount of concentrates supplied in the AMS in addition to a basic mixture fed along the feeding lane. It is also desirable to search for alternative compositions of pellets that will attract cows to enter voluntarily into the robot while reducing the inhibitory effect of the starchy pellets on NDF intake and digestion. Unfortunately, little information is available about a feeding management regimen that combines a basic bunk-fed mixture with additional individual allocations of concentrates based on a cow's individual eating frequency. These issues will be evaluated in this study using computer controlled automatic concentrate feeders (ACF) as a model of AMS to supply additive (36 $\pm 0.5 \%$ of dietary intake) of pellets composed of either starchy grains or NDF-rich by-product as starch 
replacement, to cows receiving a basic mixture $(64 \pm$ $0.5 \%$ of their DMI) along the feeding lane.

By-product feeds such as soy hulls (SH) are often favorably priced, and contain a variety of energy substrates for ruminal microbes (Van Laar et al., 1999; Miron et al., 2001). This has motivated at least 15 studies aimed at using $\mathrm{SH}$ as substitutes for corn grains in TMR of lactating cows (Ipharraguerre and Clark, 2003). However, there is limited information on the effectiveness of SH for replacing barley grain (BG) in pellets supplemented to rations of lactating cows producing around $40 \mathrm{~kg}$ of milk/d (Ipharraguerre and Clark, 2003). Moreover, there is a lack of information about the attractiveness of such pellets to motivate cows to visit a feeding-milking stall at a frequency allowing for 3 milkings a day.

Our hypothesis is that a nonroughage by-product rich in readily digestible NDF fraction, such as $\mathrm{SH}$, can successfully replace starchy grain in a pelleted additive supplied to lactating cows via ACF, while increasing NDF use for milk fat production. The nutritional aspect of this hypothesis was successfully tested in our previous study (Miron et al., 2004) using additive of $25 \%$ pellets made of $\mathrm{SH}$ and corn gluten feed as starchy grain replacement, fed individually to lactating cows on top of $75 \%$ basic TMR. However, in the previous study, no ACF were used, and it was observed that the palatability and willing consumption of the $\mathrm{SH}$ plus gluten feed pellets was somehow lower than that of the starchy pellets. It is therefore important to test a different composition of more palatable pellets containing $\mathrm{SH}$ as starch replacement that would be willingly ingested by the cows in an ACF used as a model for a robotic feeding regimen.

Objectives of this study were to conduct in vitro digestibility measurements of either high BG pellets or pellets containing $50 \% \mathrm{SH}$ as barley replacement, and to examine this hypothesis by measuring feeding behavior and milking performance of high-producing dairy cows fed, via ACF, these 2 types of pellets as additives (at $36 \pm 0.5 \%$ of dietary DM) to a basic mixture.

\section{MATERIALS AND METHODS}

\section{Cows, Diets, and Sampling Procedures}

Thirty-six lactating multiparous Holstein cows (2.4 \pm 0.10 lactations) were fed, during a 3 -wk pre-experimental period, a diet containing basic mixture submitted along the feeding lane plus supplemented starchy pellets fed in the ACF at a level of $6 \mathrm{~kg}$ of DM/cow per d (composition of basic mixture and the starchy pellets are given in Table 1). At the end of the adaptation period, cows were divided into 2 groups of 18 cows each, similar in average (mean \pm SE) stage of lactation (93 \pm
Table 1. Composition of the pellets fed in automatic computer controlled concentrate feeders (ACF) and of the basic mixture served along the feeding lane.

\begin{tabular}{lcc}
\hline & \multicolumn{2}{c}{ Dietary treatment } \\
\cline { 2 - 3 } & $\begin{array}{l}\text { SH } \\
\text { pellets }^{1}\end{array}$ & $\begin{array}{l}\text { BG } \\
\text { pellets }^{2}\end{array}$ \\
\hline Ingredients & & \\
Pellets fed in ACF, \% of dietary DM & 0 & 18.0 \\
Ground barley grains & 11.2 & 12.0 \\
Ground corn grains & 2.8 & 2.0 \\
Soybean meal & 4.0 & 4.0 \\
Extruded soy beans & 18.0 & 0 \\
Soy hulls & 64 & 64 \\
Basic mixture served, ${ }^{3} \%$ of dietary DM &
\end{tabular}

${ }^{1} \mathrm{SH}$ pellets $=$ pellets containing $50 \%$ soy hulls served in ACF.

${ }^{2} \mathrm{BG}$ pellets $=$ pellets containing $50 \%$ barley grains served in ACF.

${ }^{3}$ Basic mixture served along the feeding lane to both groups contained (kg/1000 kg of DM): barley grain, 109.4; corn grain, 98.8; cotton grains, 62.5; soybean meal, 151.3; sunflower meal, 22.5; oat hay, 82.5; corn silage, 82.5; vetch hay, 43.1; wheat silage, 292.5; protected fat, 12.5 ; ammonium sulfate, 1.25 ; calcium carbonate, 25 ; dicalcium phosphate, 3.75; magnesium oxide, 3.27; sodium bicarbonate, 8.13 ; trace minerals and vitamin mix, 1.0 (Miron et al., 2004).

$6.3 \mathrm{~d}$ in milking), daily milk yield (40.4 $\pm 0.85 \mathrm{~kg})$, and BW $(555 \pm 8.2 \mathrm{~kg})$. The barn and ACF were under continuous lighting. The ACF used for individual concentrated pellets feeding in this study was a dual-channel version of the system described previously by Livshin et al. $(1995,2002)$. The ACF is a product of Kibutz Afikim, Israel, and is equipped for electronic identification of individual cows, and computerized control and recording of their entry into the feed stalls, where the ACF facilitate the monitoring and analysis of the pellets intake and feeding behavior of each cow in the group. Recognition of each cow registered by the electronic system allowed submission of a given amount of BG or SH pellets to each cow. Two dual-channel ACF were used and each of them could suspend both kinds of pellets (BG and $\mathrm{SH}$ ) in a similar rate (280 to $320 \mathrm{~g} /$ min), each from a different channel. All the cows, experimental and control animals, were kept in one shaded corral as a single group, had free access to water, and were milked daily at 0500,1300 , and $2100 \mathrm{~h}$. The experiment was conducted during December 2003 and January 2004 for 6 wk after an adaptation period to diets of 3 wk. Each cow was offered individually $9 \mathrm{~kg}$ of DM/ $\mathrm{d}$ of the concentrated pellets. Pellets were fed diurnally in equal portions of $1.5 \mathrm{~kg}$ in 6 feeding windows (FW) every 3 to $5 \mathrm{~h}$ as described in previous studies (Devir, 1995; Livshin et al., 1995, 2002). Unconsumed amounts from a FW were transferred in equal portions to the 6 coming FW with a limitation of a maximum $5-\mathrm{kg}$ allowance in any one FW. Feeding windows were opened 6 times/d (3 of them when cows returned from the milking parlor) at: 0030, 0530, 0930, 1330, 1730, and $2115 \mathrm{~h}$. The feeders were calibrated weekly and 
any time a new batch of concentrates was delivered. The cows had free access to the basic mixture submitted along the feeding lane. The average basic mixture intake by all cows (fed as a single group) was estimated based on daily weighing of the basic mixture submitted to the cows and their orts left in the feeding lane. Diets were designed to supply to each cow with $16 \mathrm{~kg}$ of DM/ $\mathrm{d}$ of basic mixture plus $9 \mathrm{~kg}$ of $\mathrm{DM} / \mathrm{d}$ pelleted additive fed in the ACF. Thus, each of the experimental diets contained $64 \pm 0.5 \%$ of a basic mixture (1.63 Mcal NE $\mathrm{N}_{\mathrm{L}}$, $17 \% \mathrm{CP}$ on a DM basis) served once daily at $1000 \mathrm{~h}$, plus $36 \pm 0.5 \%$ additive of starchy or $\mathrm{SH}$ pellets fed via the ACF. Detailed composition of the 2 types of pellets and of the base mixture are shown in Table 1. The high starch pellets were composed of $50 \%$ barley plus corn grain, soybean meal, and extruded soy beans (BG pellets); the NDF-rich pellets were composed of SH as barley replacement plus small adjustments between corn and soybean meal (SH pellets) to achieve a similar $\mathrm{CP}$ content (17\%) in both pellets. This was essential to create a feeding regimen similar to that of an AMS while allowing the cows ad libitum intake of the basic mixture that also contained $17 \% \mathrm{CP}$. The 2 types of pellets slightly differed in their calculated net energy content (1.93 and $1.98 \mathrm{Mcal}$ of $\mathrm{NE}_{\mathrm{L}} / \mathrm{kg}$ of $\mathrm{DM}$ in $\mathrm{SH}$ and $\mathrm{BG}$ pellets, respectively). Values for $\mathrm{NE}_{\mathrm{L}}$ of the individual feeds used in this study were provided by the pellets manufacturers (Matmor Co., Ashdod, Israel) and used to summarize $\mathrm{NE}_{\mathrm{L}}$ content of the basic mixture and the 2 types of pellets.

Behavior of cows was analyzed based on the data collected in the computer system that monitored cow visits and intake of pellets at the ACF. Feeding behavior data, including number of meals per day, duration of visits and food consumption during each visit and each day, as well as distribution of rewarded and unrewarded visits throughout the day, were recorded and analyzed for individual cows as described previously (Livshin et al., 1995, 2002). In this study, a cow pellet meal was defined as an identified rewarded visit in an ACF trough that lasted at least 1 min while eating at least $0.1 \mathrm{~kg}$ of pellets.

The basic mixture and the 2 kinds of pellets were sampled and pooled on a weekly basis to produce 6 composites. Dry matter intake was determined by drying a portion of the base mixture and pellets at $105^{\circ} \mathrm{C}$ for $24 \mathrm{~h}$. The weekly pooled samples of basic mixture and 2 types of pellets were oven-dried at $60^{\circ} \mathrm{C}$ for 48 $\mathrm{h}$, ground through a $1-\mathrm{mm}$ screen, and used to determine the extent and rate of in vitro digestibility of the DM and NDF fractions, and for chemical analyses.

Milk yield was recorded daily by automatic meters (Afimilk, Israel). Milk samples were collected during 3 sequential milkings on Wednesday of each week during the 6-wk experimental period. Each set of milk samples for each cow was stored at $4^{\circ} \mathrm{C}$ in the presence of a conservation pill, until analyzed for content of fat, true protein, lactose, urea, and SCC, by infrared analysis (Dairy Milk Association Laboratory, Caesaria, Israel) using the Milkoscan 4000 (Foss Electric, Hillerød, Denmark).

\section{Chemical Analyses and In Vitro Digestibility}

Samples of oven-dried basic mixture and the 2 types of pellets ( 6 pooled samples collected weekly) were assayed in triplicate for $\mathrm{DM}$ and $\mathrm{OM}$ (procedures 7.007 and 7.009 in AOAC, 1980); CP was determined according to a Kjeldahl method (procedure 7.021 in AOAC, 1980). The NDF, ADF, and acid detergent lignin contents were determined in the basic mixture and 2 pellets in triplicate as well as NDF analyzed in the in vitro residues, according to the method of Van Soest et al. (1991), with $\alpha$-amylase, without sodium sulfite, and by employing Ankom apparatus (Ankom ${ }^{220}$, Fairport, NY) for extraction and filtering.

Extent of DM and NDF in vitro digestibility of the 2 pellets was analyzed in each weekly pooled sample in triplicate using $48 \mathrm{~h}$ of incubation with rumen fluid followed by an additional 48-h incubation with $\mathrm{HCl}$ and pepsin, according to the 2-stage fermentation technique of Tilley and Terry (1963). Ruminal fluid free of saliva contamination was obtained before morning feeding via esophageal tube from 4 cows fed the $\mathrm{SH}$ pellets and from 4 cows fed the BG pellets, and combined to create one pooled sample to be used for the in vitro measurements. Rate of in vitro DM and NDF digestibility of the 2 types of pellets was measured similarly except that the first stage of incubation was conducted in triplicate during $0,6,12,24,48$, or $72 \mathrm{~h}$ of fermentation with rumen fluid followed by a further 48-h fermentation with $\mathrm{HCl}$ and pepsin. Rate of DM and NDF digestion was determined as the slopes of the first-order kinetic equation describing the regression between $\log _{\mathrm{e}}$ (Residual fraction \% - undigested fraction \%) against time of incubation (h), as shown by Mertens and Loften (1980).

\section{Calculations and Statistical Analyses}

The daily yield per cow of $4 \% \mathrm{FCM}$ and the payment equation (economically-corrected milk, ECM) were calculated according to the equation used by the Israeli Dairy Milk Association (Miron et al., 2004):

$$
\begin{gathered}
4 \% \text { FCM }(\mathrm{kg})=0.4 \times \text { milk }(\mathrm{kg})+15.0 \times \text { milk fat }(\mathrm{kg}) \\
\mathrm{ECM}(\mathrm{kg})=9.436 \times \text { milk fat }(\mathrm{kg}) \\
+22.018 \times \text { milk protein }(\mathrm{kg})
\end{gathered}
$$


Differences between the 2 pellets regarding the extent and rate of DM and NDF in vitro digestibility were analyzed statistically (Jump 5 software, using Tukey's test to differentiate between means).

Feeding behavior data for the individual cows fed in the $\mathrm{ACF}$, as well as milking performance and $\mathrm{BW}$ data, were reduced to means by cow in the $42 \mathrm{~d}$ of the experimental period after the 21-d adaptation period to the diets. This data was analyzed in completely randomized design by ANOVA using the GLM procedure of SAS (SAS Institute, 1996). Because cows were allocated to 2 groups similar in their performance and DIM at the onset of the experiment, there was no need for covariate adjustments. Repeated measures analysis on a weekly basis showed lack of any interaction between time of trial duration and the parameters of milk yield, milk composition, and feeding behavior. Figure 1 shows repeated measures on a weekly basis of milk, fat, and protein yields.

\section{RESULTS AND DISCUSSION}

\section{Composition and In Vitro Digestibility of Pellets and Basic Mixture}

The 2 rations differed in the composition of the pellets added at the ACF (as 36\% of the dietary DM), containing either high starch in the BG group vs. SH group (Table 1). Total NDF content was higher in the $\mathrm{SH}$ pellets than in the BG pellets (44.1 and $24.2 \%$, respectively, Table 2), and this was reflected by the higher NDF content of the SH ration compared with the BG diet (45.3 and $38.1 \%$, respectively). Both groups received similar level of forage NDF (17.5\%); however, in the SH ration, most NDF was of nonroughage origin $(\sim 53 \%)$, whereas in the BG diet, $59 \%$ of the NDF originated from roughage. This difference in dietary NDF content and origin exerted not only quantitative but also a qualitative difference between the 2 diets, since the extent and rate of NDF in vitro digestibility of the $\mathrm{SH}$ pellets $(82.0 \%$ and $5.69 \% / \mathrm{h}$, respectively) were higher $(P<0.03)$ than those of the BG pellets $(66.7 \%$ and $4.33 \% / \mathrm{h})$, as shown in Table 2. The higher NDF digestibility of the $\mathrm{SH}$ pellets is a result of the high digestibility of $\mathrm{SH}$ NDF-polysaccharides compared with that of NDF obtained from barley (Ben-Ghedalia and Solomon, 1987; Miron et al., 2001). However, the extent and rate of DM in vitro digestibility were similar in both pellets (86.4 to $87.9 \%$ and $~ 7.7 \% / \mathrm{h}$, respectively, Table 2 ). Because the DM digestibility, calculated energy (1.73 to 1.75 Mcal of $\mathrm{NE}_{\mathrm{I}} / \mathrm{kg}$ of $\mathrm{DM}$ ) and $\mathrm{CP}$ content $(17 \%)$ of the 2 diets were similar, fiber and starch differences between the 2 types of pellets, as described above, would be expected to explain any differences in observed lactation performance or feeding behavior.
A

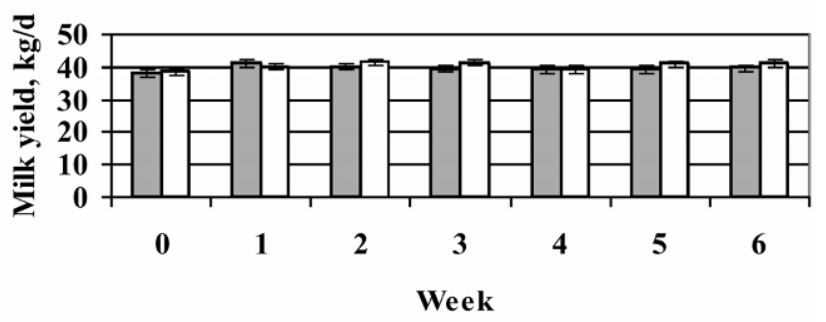

$\square$ SH pellets $\square$ BG pellets

B

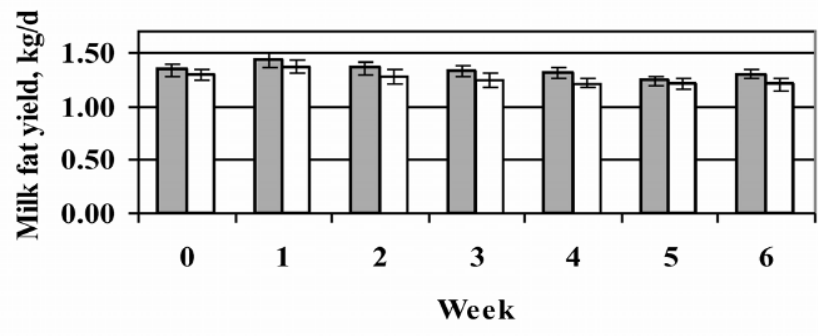

$\square$ SH pellets $\square$ BG pellets

C

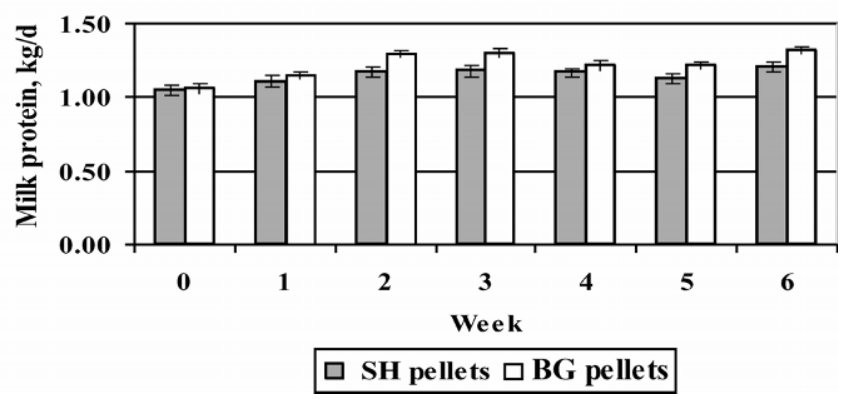

Figure 1. Yields of A) milk, B) milk fat, and C) milk protein (kg/ d) of cows fed soy hulls (SH) pellets or barley grain (BG) pellets during the $6 \mathrm{wk}$ of the experiment, compared with the pre-experimental period (Week 0).

\section{Feeding Behavior in the ACF}

Feeding behavior data of $\sim 11,000$ visits of the cows in the ACF were analyzed; average results are summarized in Table 3 and Figure 2. The 2 feeders were visited equally by cows in both dietary groups, and at a similar frequency. It seems that the type of pellets did not affect feeding or visiting behavior. All parameters of feeding behavior were similar (Table 3 ). The cows responded to FW opening by visiting the ACF during at least 4 FW in each day, consuming $80 \%$ of the FW ration within $2 \mathrm{~h}$ of FW start, and eating pellets during day and night hours (Figure 2). A similar response of cows to FW opening and diurnal eating behavior in $\mathrm{ACF}$ was pre- 
Table 2. Chemical composition and in vitro digestibility of the 2 pellets and basic mixture.

\begin{tabular}{|c|c|c|c|c|}
\hline & \multicolumn{2}{|c|}{ Dietary treatment } & \multirow[b]{2}{*}{ Basic mixture $^{3}$} & \multirow[b]{2}{*}{ SEM } \\
\hline & SH pellets ${ }^{1}$ & BG pellets ${ }^{2}$ & & \\
\hline \multicolumn{5}{|l|}{ Dietary component $(\% \pm \mathrm{SD}$ of $\mathrm{DM})$} \\
\hline DM, \% & $88.5 \pm 1.0$ & $88.9 \pm 1.2$ & $54.7 \pm 1.4$ & $\ldots$ \\
\hline $\mathrm{CP}$ & $16.9 \pm 0.1$ & $17.0 \pm 0.1$ & $17.0 \pm 0.2$ & $\ldots$ \\
\hline NDF from roughage & & & $27.3 \pm 0.2$ & $\ldots$ \\
\hline Total NDF & $44.1 \pm 1.1$ & $24.2 \pm 1.2$ & $46.0 \pm 1.4$ & $\ldots$ \\
\hline Cellulose & $25.4 \pm 1.1$ & $5.50 \pm 0.2$ & $20.7 \pm 0.7$ & $\ldots$ \\
\hline Hemicellulose & $17.0 \pm 0.1$ & $17.2 \pm 0.3$ & $18.8 \pm 0.6$ & $\ldots$ \\
\hline Acid detergent lignin & $1.72 \pm 0.08$ & $1.48 \pm 0.24$ & $6.49 \pm 0.30$ & . \\
\hline Calculated $\mathrm{NE}_{\mathrm{L}}, \mathrm{Mcal} / \mathrm{kg}$ of $\mathrm{DM}$ & 1.93 & 1.98 & 1.62 & \\
\hline \multicolumn{5}{|l|}{ Extent of in vitro digestibility, \% } \\
\hline DM & $87.9^{\mathrm{a}}$ & $86.4^{\mathrm{a}}$ & $70.5^{b}$ & 1.33 \\
\hline NDF & $82.0^{\mathrm{a}}$ & $66.7^{\mathrm{b}}$ & $53.4^{\mathrm{c}}$ & 1.42 \\
\hline \multicolumn{5}{|l|}{ Rate of in vitro digestibility, $\% / \mathrm{h}$} \\
\hline DM of added pellets & $7.80^{\mathrm{a}}$ & $7.61^{\mathrm{a}}$ & $5.13^{\mathrm{b}}$ & 0.23 \\
\hline NDF of added pellets & $5.69^{\mathrm{a}}$ & $4.33^{\mathrm{b}}$ & $4.17^{\mathrm{b}}$ & 0.21 \\
\hline
\end{tabular}

a,b,c Means in the same row followed by different superscripts differ at $P<0.05$.

${ }^{1} \mathrm{SH}$ pellets $=$ pellets containing $50 \%$ soy hulls served in automatic concentrate feeders.

${ }^{2} \mathrm{BG}$ pellets $=$ pellets containing $50 \%$ barley grains served in automatic concentrate feeders.

${ }^{3}$ Basic mixture was served along the feeding lane to both groups.

viously demonstrated by Livshin et al. (1995, 2002), who supplied starchy pellets to milking cows via ACF. From the similarity between the 2 types of pellets with respect to number of unrewarded visits and maximal interval between visits, it can be concluded that the $\mathrm{SH}$ pellets are palatable and attractive to cows in a similar manner to the BG pellets. Thus, under similar circumstances of basic mixture composition and pellet allocation, the SH pellets can be effectively used as starchy pellet replacer, to attract cows to enter into an AMS.
Maximum time interval between ACF visits (8.5 to 9.0 $\mathrm{h}$, Table 3 ) and average visited FW, indicate an average of 4 potential FW visits and a minimum of 2 visits per day executed for all cows visiting the ACF. This behavior indicates a pattern that may permit, under the same feeding conditions, an average of 4 milkings per day in an AMS. Cows fed the 2 types of pellets had a similar number of voluntary pellet meals per day (4.8) and consumed a similar amount of pellets per meal (1.8 $\mathrm{kg}$ of $\mathrm{DM} / \mathrm{meal}$ ) and per day (8.64 kg of DM/d, Table

Table 3. Feeding behavior in automatic concentrate feeders (ACF) of cows supplemented with 2 types of pellets.

\begin{tabular}{|c|c|c|c|c|}
\hline \multirow[b]{2}{*}{ Variable } & \multicolumn{2}{|c|}{ Dietary treatment } & \multirow[b]{2}{*}{ SEM } & \multirow[b]{2}{*}{$P$} \\
\hline & SH pellets ${ }^{1}$ & BG pellets ${ }^{2}$ & & \\
\hline No. of all ACF visits/cow per $d$ & 8.60 & 9.12 & 0.25 & 0.14 \\
\hline Unvisited $\mathrm{FW}^{3} /$ cow per d & 1.90 & 1.85 & 0.62 & 0.30 \\
\hline Maximal interval between visits, $\mathrm{h} /$ cow per $\mathrm{d}$ & 9.07 & 8.83 & 0.22 & 0.46 \\
\hline No. of rewarded visits, pellet meals/cow per d & 4.50 & 4.67 & 0.08 & 0.14 \\
\hline Duration of eating in $\mathrm{ACF}$, $\mathrm{min} / \mathrm{cow}$ per $\mathrm{d}$ & 50.07 & 54.25 & 1.40 & 0.08 \\
\hline Average meal duration, min/meal & 11.13 & 11.62 & 0.29 & 0.36 \\
\hline Pellets intake in rewarded visits, $\mathrm{kg}$ of $\mathrm{DM} / \mathrm{meal}$ & 1.92 & 1.85 & 0.08 & 0.62 \\
\hline Pellets intake, $\mathrm{kg} \mathrm{DM} /$ cow per d & 8.64 & 8.64 & 0.09 & 0.85 \\
\hline Predicted DMI ${ }^{4} \mathrm{~kg} / \mathrm{cow}$ per d & 23.70 & 23.44 & 0.39 & $\ldots$ \\
\hline Predicted BM intake, ${ }^{5} \mathrm{~kg}$ of $\mathrm{DM} /$ cow per $\mathrm{d}$ & 15.06 & 14.8 & 0.37 & $\cdots$ \\
\hline Predicted NDF intake, kg/cow per d & 10.73 & 8.90 & 0.38 & $\ldots$ \\
\hline
\end{tabular}

${ }^{1} \mathrm{SH}$ pellets $=$ pellets containing $50 \%$ soy hulls served in ACF.

${ }^{2} \mathrm{BG}$ pellets = pellets containing $50 \%$ barley grains served in ACF

${ }^{3} \mathrm{FW}=$ Feeding windows.

${ }^{4}$ Predicted DMI calculated according to NRC (2001), based on individual FCM production, BW, and DIM of the cows in each group.

${ }^{5} \mathrm{BM}=$ Basic mixture served along the feeding lane to both groups. Prediction of BM intake is calculated as total predicted DMI - pellets DM intake of each cow. Predicted NDF intake is calculated based on predicted DMI data multiple by NDF content (Table 2). 


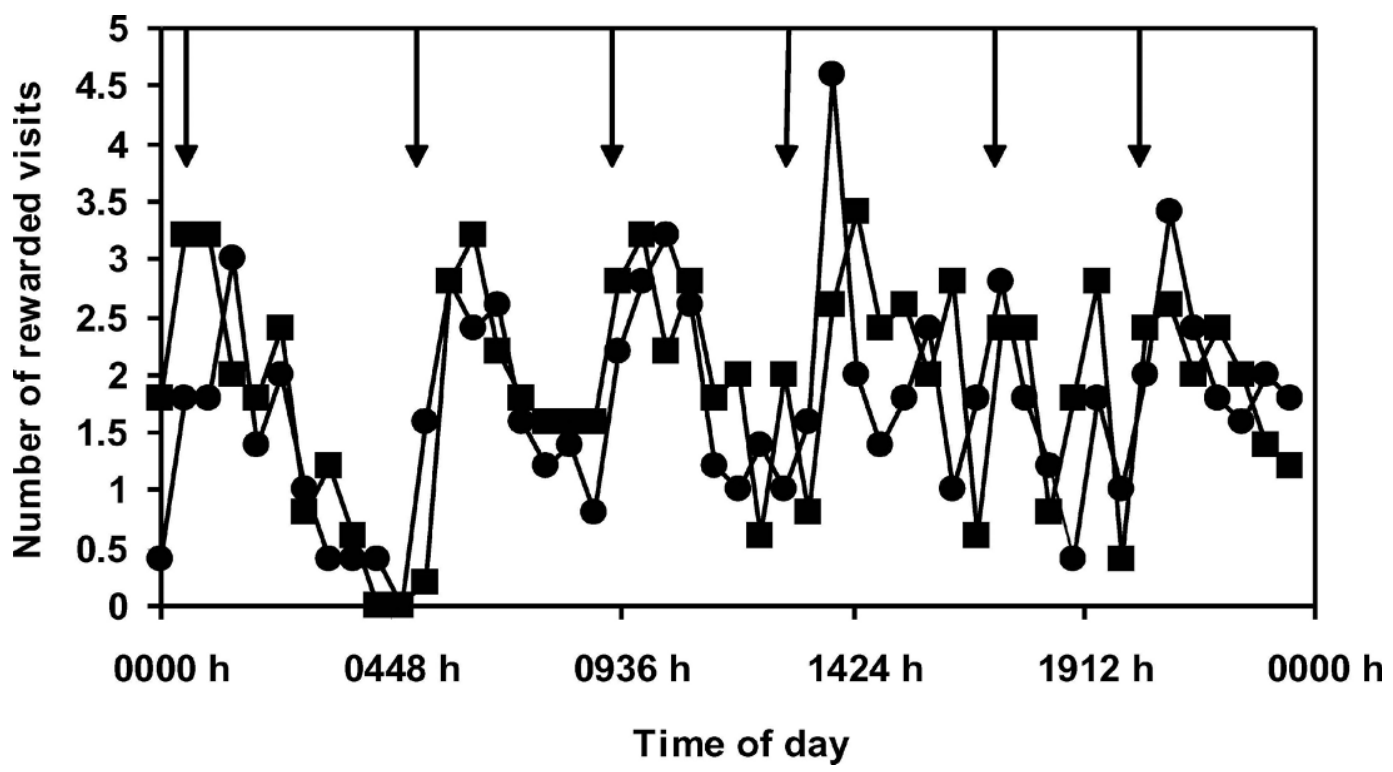

Figure 2. Diurnal feeding pattern. Number of meals distributed in the automatic concentrates feeders (ACF) over an average day, during 2 representative weeks of the experiment. Cows received either soyhulls (SH) pellets (-) or barley grain (BG) pellets ( $\mathbf{\square})$. Arrows indicate opening of a feeding window (FW). Data suggest similar feeding behavior during day and night for both groups, with animals consuming most of their pellet meals within $2 \mathrm{~h}$ of each FW opening.

3). This data probably reflects the similarity in extent and rate of $\mathrm{DM}$ digestibility and $\mathrm{NE}_{\mathrm{L}}$ content of the 2 pellets (Table 2), as shown in our previous study (Miron et al., 2004). The extent of DM consumption from pellet meals was similar in both groups $(8.64 \mathrm{~kg} / \mathrm{d}$, Table 3$)$. However, the intake of the basic mixture along the feeding lane was group-measured (rather than for individual cow), and was estimated (based on amount offered to each group and residues weighed along the feeding lane) to be $15.1 \mathrm{~kg}$ of $\mathrm{DM} / \mathrm{cow}$ per d. To get a better estimation of DMI for each of the dietary treatments, we used the NRC DMI prediction equation (NRC, 2001) to predict the daily DMI of each cow used in the experiment. Based on the NRC equation, similar total DMI was obtained in the SH and BG groups (23.7 and $23.4 \mathrm{~kg} / \mathrm{d}$, respectively), a value that matched the sum of pellets ingested plus estimated group fed basic mixture intake $(8.6+\sim 15.1=23.7 \mathrm{~kg}$ of $\mathrm{DM} / \mathrm{d}$ in both groups). This similar DMI of the 2 dietary groups (Table 3 ) is in accord with some previous studies that showed similar DMI in cows fed $\mathrm{SH}$ as a replacement for 18 to $25 \%$ corn grains (Elliot et al., 1995; Ipharraguerre and Clark, 2003). It should be emphasized that due to the differences in NDF content (Table 2), the accumulative predicted NDF intake was significantly higher in the SH cows compared with the BG group (10.7 vs. 8.90 $\mathrm{kg} / \mathrm{d}$, respectively, Table 3).

\section{Milk Yield and Composition}

Milk yield and composition data during the experimental period are shown in Table 4; and repeated measurements on a weekly basis for milk, protein, and fat yields are presented in Figure 1. Average milk yield and lactose content were similar in cows fed the 2 types of pellets (Table 4) and during the 6 wk of the experiment (Figure 1). This finding may be due to the similar-

Table 4. Performance of cows fed a basic mixture plus 2 types of pellets supplemented in automatic concentrate feeders (ACF).

\begin{tabular}{|c|c|c|c|c|}
\hline \multirow[b]{2}{*}{ Variable } & \multicolumn{2}{|c|}{ Dietary treatment } & \multirow[b]{2}{*}{ SEM } & \multirow[b]{2}{*}{$P$} \\
\hline & SH pellets ${ }^{1}$ & BG pellets ${ }^{2}$ & & \\
\hline Milk yield, $\mathrm{kg} / \mathrm{d}$ & 39.6 & 40.8 & 0.94 & 0.37 \\
\hline Milk fat, $\%$ & $3.37^{\mathrm{a}}$ & $3.09^{b}$ & 0.09 & 0.05 \\
\hline Milk protein, \% & $2.92^{\mathrm{a}}$ & $3.06^{\mathrm{b}}$ & 0.03 & 0.01 \\
\hline Milk lactose, $\%$ & 4.96 & 4.97 & 0.06 & 0.89 \\
\hline Milk urea, \% & $0.035^{\mathrm{a}}$ & $0.029^{b}$ & 0.001 & 0.01 \\
\hline Milk fat, $\mathrm{kg} / \mathrm{d}$ & 1.33 & 1.26 & 0.04 & 0.22 \\
\hline Milk protein, $\mathrm{kg} / \mathrm{d}$ & 1.16 & 1.25 & 0.03 & 0.06 \\
\hline $4 \%$ FCM yield, $\mathrm{kg} / \mathrm{d}$ & 35.9 & 35.2 & 0.81 & 0.58 \\
\hline ECM yield,${ }^{3} \mathrm{~kg} / \mathrm{d}$ & 37.9 & 39.1 & 0.87 & 0.36 \\
\hline Average BW, kg & 560 & 558 & 11.1 & 0.86 \\
\hline
\end{tabular}

${ }^{\mathrm{a}, \mathrm{b}}$ Means in the same row following by different superscripts differ at $P<0.05$.

${ }^{1} \mathrm{SH}$ pellets $=$ pellets containing $50 \%$ soy hulls served in ACF.

${ }^{2} \mathrm{BG}$ pellets $=$ pellets containing $50 \%$ barley grains served in $\mathrm{ACF}$.

${ }^{3} \mathrm{ECM}=$ Economically-corrected milk. 
ity in pellets intake, DM digestibility, and calculated $\mathrm{NE}_{\mathrm{L}}$ of the 2 diets (Tables 2 and 3). Average concentration of milk fat was significantly greater in the $\mathrm{SH}$ group (3.37 vs. $3.09 \%$ ) whereas average concentration of milk protein was significantly higher in the BG cows (3.06 vs. $2.92 \%)$. Consequently, average protein yield tended to be higher in the BG cows (Table 4), and this slight advantage was maintained during most weeks of the experimental period (Figure 1). On the other hand, milk fat yield tended to be greater in the $\mathrm{SH}$ cows (Table 4) and was maintained throughout the experimental period (Figure 1). The improved milk protein content in BG-fed cows is probably due to the higher level of grain carbohydrate ingested (Tables 2 and 3), which may encourage propionate and microbial protein synthesis in the rumen and greater AA absorption in the lower gut, leading to more milk protein production (Miron et al., 1996). The lower urea content in milk of the cows fed the BG pellets suggests there is better synchronization of carbohydrate and ammonia $\mathrm{N}$ in their rumens to produce microbial protein, compared with the SH-fed cows. A similar trend with respect to milk protein was obtained in our previous study comparing barley-rich vs. SH-rich TMR fed to lactating cows (Miron et al., 2004).

On the other hand, the slight advantage of the $\mathrm{SH}$ cows in milk fat content and FCM production may be due to the higher daily NDF intake and higher extent of NDF in vitro digestibility of that ration as compared with the BG group (Tables 2 and 3). More digestible cellulose and hemicellulose usually results in production of more acetate by rumen cellulolytic bacteria (Chesson and Forsberg, 1997), which can be used as a precursor for milk fat synthesis in the mammary gland. Thus, the improvement in milk fat production of the $\mathrm{SH}$ cows is probably the result of supplementation of more digestible NDF and creation of favorable conditions for microbial fiber degradation in the rumen of cows fed the SH pellets (Miron et al., 2004). These data are supported by results from previous studies, which showed that replacement of corn grain or barley with SH in cows' TMR (18 to $20 \%$ of dietary DM) tended to increase milk fat content and FCM yield in lactating cows while reducing milk protein content and yield (Elliot et al., 1995; Ipharraguerre et al., 2002; Miron et al., 2004). Similar reduction in milk fat content was obtained in cows fed basic mixture along the feeding lane plus starchy pellets at ACF compared with a conventional TMR feeding regimen (Maltz et al., 1991, 1992).

The present study showed that the composition of the SH pellets fed up to $36 \%$ of dietary DM is adequate to make their palatability and voluntary ingestion similar to that of conventional starchy pellets. The SH pel- lets are comparable to the BG pellets with respect to their effect on milk and ECM production. Thus, the SH pellets can be used as an alternative for starchy pellets in robotic systems, especially in situations where enhancement of milk fat production is required.

\section{CONCLUSIONS}

Inclusion of SH as a replacement for barley grains in pelleted additive fed to high-producing cows increased NDF intake and digestibility. Consequently, milk yield was maintained and milk fat content in lactating cows was enhanced, probably as the result of supplementation of more digestible NDF and creation of favorable conditions for microbial fiber degradation in the rumen of cows fed the SH pellets. On the other hand, replacement of BG pellets with $\mathrm{SH}$ pellets reduced milk protein content, probably as the result of less grain carbohydrate supplementation to the rumen of the $\mathrm{SH}$ cows and less microbial protein production compared with the BG cows. Feeding behavior data suggest similar palatability of both types of pellets, indicating that the SH pellets may be recommended for AMS as replacement for the conventional starchy pellets, allowing for an average of 4 milkings per day, and enhancing milk fat content whenever desired.

\section{ACKNOWLEDGMENTS}

The authors acknowledge the assistance given by the farm staff at the Bet-Dagan dairy barn, ARO, Israel, with special thanks to S. Yakobi, Y. Portnick, L. Gurevitz, and Y. Brender. The authors also thank Z. Sarid from Yavne Feed Center, Israel, and Y. Shpirer from Matmor Feedmill, Israel, for the preparation of basic mixture and pellets, and to M. Geeps from the Israeli Dairy Cattle Association Central Lab, for milk analyses.

\section{REFERENCES}

Association of Official Analytical Chemists. 1980. Official Methods of Analysis. 13th ed. AOAC, Arlington, VA.

Ben-Ghedalia, D., and R. Solomon. 1987. The effect of dietary barley on carbohydrate digestibility of sulfur dioxide treated wheat straw by sheep. Anim. Feed Sci. Technol. 18:55-66.

Chesson, A., and C. W. Forsberg. 1997. Polysaccharides degradation by rumen microorganisms. Pages 329-381 in The Rumen Microbial Ecosystem, 2nd ed. P. N. Hobson and C. S. Stewart, ed. Blackie Academic and Professional, London, UK.

Devir, S. 1995. The dairy control and management system in the robotic milking barn. $\mathrm{Ph}$. D. Thesis. Landbouwuniversiteit Wageningen (In English with summary in Dutch and Hebrew), Wageningen Press, The Netherlands.

Elliot, J. P., J. K. Drackley, G. C. Fahey, Jr., and R. D. Shanks. 1995. Utilization of supplemental fat by dairy cows fed diets varying in content of nonstructural carbohydrates. J. Dairy Sci. $78: 1512-1525$. 
Halachmi, I. 1999. Design methodology for a robotic milking barn: Modelling, Simulation, Validation, and Optimization. Ph.D. Thesis, Wageningen University, Wageningen Press, The Netherlands.

Halachmi, I. 2004. Designing the automatic milking farm in a hot climate. J. Dairy Sci. 87:764-775.

Ipharraguerre, I. R., and J. H. Clark. 2003. Soyhulls as alternative feed for lactating cows. J. Dairy Sci. 86:1052-1073.

Ipharraguerre, I. R., R. R. Ipharraguerre, and J. H. Clark. 2002. Performance of lactating dairy cows fed varying amounts of soy hulls as a replacement for corn grains. J. Dairy Sci. 85:2905-2912.

Livshin, N., E. Maltz, and A. Antler. 2002. Adaptation of dairy cows to change in computer controlled concentrates feeding routine. J. Anim. Feed Sci. 11:19-37.

Livshin, N., E. Maltz, and Y. Edan. 1995. Regularity of dairy cow feeding behavior to computer controlled feeding. J. Dairy Sci. 78:296-304.

Maltz, E., S. Devir, O. Kroll, B. Zur, S. L. Spahr, and R. D. Shanks. 1992. Comparative responses of lactating cows to total mixed ration or computerized individual concentrates feeding. J. Dairy Sci. 75:1588-1603.

Maltz, E., O. Kroll, R. Sagi, S. Devir, S. L. Spahr, and A. Genizi. 1991. Milk yield, parity and cow potential as variables for computerized concentrates supplementation strategy. J. Dairy Sci. 74:22772289.

Mertens, D. R., and J. R. Loften. 1980. The effect of starch on forage fiber digestion kinetics in vitro. J. Dairy Sci. 63:1437-1444.

Miron, J., R. Solomon, I. Bruckental, and D. Ben-Ghedalia. 1996. Effect of changing the proportion, wheat:sorghum in dairy cow rations on carbohydrate digestibility and NAN flow to the intestine. Anim. Feed Sci. Technol. 57:75-86.

Miron, J., E. Yosef, and D. Ben-Ghedalia. 2001. Composition and in vitro digestibility of monosaccharide constituents of selected byproduct feeds. J. Agric. Food Chem. 49:2322-2326.

Miron, J., E. Yosef, M. Nikbachat, A. Zenou, E. Maltz, I. Halachmi, and D. Ben-Ghedalia. 2004. Feeding behavior and performance of dairy cows fed pelleted nonroughage fiber by-products. J. Dairy Sci. 87:1372-1379

Morita, S., S. Devir, C. C. Ketelaar-De Lauwere, A. C. Smits, H. Hogeveen, and J. H. M. Metz. 1996. Effects of concentrate intake on subsequent roughage intake and eating behavior of cows in an automatic milking system. J. Dairy Sci. 79:1572-1580.

National Research Council. 2001. Nutrient Requirements of Dairy Cattle, 7th rev. ed. Natl. Acad. Press, Washington, DC.

SAS Institute. 1996. SAS User's Guide: Statistics, version 6.12. SAS Institute Inc., Cary, NC.

Tilley, J. M., and R. M. Terry. 1963. A two-stage technique for the in vitro digestion of forage crops. J. Br. Grassland Soc. 18:104-111.

Van Laar, H., S. Tamminga, B. A. Williams, M. W. A. Verstegen, and F. M. Engels. 1999. Fermentation characteristics of cell wall sugars from soybean hulls, and from separated endosperm and hulls of soybeans. Anim. Feed Sci. Technol. 79:179-193.

Van Soest, P. J., J. B. Robertson, and B. A. Lewis. 1991. Methods for dietary fiber, neutral detergent fiber, and non-starch polysaccharides in relation to animal nutrition. J. Dairy Sci. 74:35833597.

Wagner-Storch, A. M., and R. W. Palmer. 2003. Feeding behavior, milking behavior, and milk yields of cows milked in a parlor versus an automatic milking system. J. Dairy Sci. 86:1494-1502. 